\title{
Libertad de expresión y responsabilidad social en
}

tiempos pandemia

Freedom of expression and social responsibility in times of pandemic

Marina del Pilar Olmeda García ${ }^{1}$

: IUS Comitiâlis / Año 3, Número 6 / julio - diciembre 2020 / pp. 131-149 / ISSN: 2594-1356

Recepción: 12 de junio de 2020 / Aceptación: 27 de septiembre de 2020

Resumen: El objetivo de este estudio es reflexionar sobre el derecho humano a la libertad de expresión y destacar la responsabilidad social en el ejercicio de este derecho. En particular, en este estudio se realiza un análisis del derecho humano a la libertad de expresión a través de la revisión de la producción teórica y del avance normativo del reconocimiento a este derecho. El trabajo integra, además, un breve contexto histórico del desarrollo normativo del reconocimiento al derecho a la libertad de expresión y el recorrido de su camino, que lo concretizan como un derecho humano superior. Se concluye con la reflexión sobre la responsabilidad social en el ejercicio de este derecho, particularmente cuando se trata de una pandemia como la tragedia que vive la humanidad en el presente que impacta todos los ámbitos de la vida humana.

Palabras clave: Libertad de expresión, responsabilidad social, pandemia.

Abstract: The objective of this study is to reflect on the human right to freedom of expression and highlight social responsibility in the exercise of this right. In particular, in this study is carried out an analysis of the human right to freedom of expression through the review of the theoretical production and the normative advance of the recognition of this right. The work also includes a brief historical context of the normative development of the recognition of the right to freedom of expression and the path of its path, which concretize as a superior human right. It concludes with a reflection on the social responsibility in the exercise of this right, particularly when it comes to a pandemic like the tragedy that humanity lives in the present that impacts all areas of human life.

Key words: Freedom of expression, social responsibility, pandemic.

https://orcid.org/0000-0002-3953-0338. / Correo electrónico: olmedamp@hotmail.com

${ }^{1}$ Doctora en Educación, por la Universidad Iberoamericana y Estudios de Doctorado en Derecho Constitucional por la Universidad de Castilla La Mancha. Profesora - Investigadora de TC, Titular nivel C, en la Facultad de Derecho Mexicali de la Universidad Autónoma de Baja California, México. Integrante del Sistema Nacional de Investigadores, SNI-ll Certificación PRODEP. Lideresa del Cuerpo Académico Estudios Sociales y Jurídicos, Derechos Humanos y Seguridad Pública. 


\section{INTRODUCCIÓN}

El presente trabajo es uno de los productos de una línea de investigación amplia que se realiza en la Universidad Autónoma de Baja California sobre derecho constitucional y derechos humanos, en el que participa la autora. En particular, en este estudio se realiza un análisis del derecho humano a la libertad de expresión a través de la revisión de la producción teórica y del avance normativo del reconocimiento a este derecho. Se realiza un recorrido del régimen normativo de este derecho en México, del camino que lo concretiza como un derecho humano superior que a la vez tiene sus límites, uno de ellos muy importante es la responsabilidad social para ayudar a tomar decisiones adecuadas ante una enfermedad como la que enfrenta en el presente la humanidad. Se pretende ponderar la importancia del derecho humano a la libertad de expresión y la función que tienen los sistemas de información y de la comunicación durante la pandemia que se vive, en la que resalta la responsabilidad social.

La metodología aplicada en relación con este trabajo se realizó a través del análisis doctrinal y normativo con un tratamiento cualitativo, con apoyo en los métodos deductivo, analítico y dialectico. Asimismo, se aplicaron métodos cuantitativos para la revisión de insumos estadísticos, sin olvidar las políticas públicas y acciones gubernamentales, además de experiencias internacionales exitosas.

En la organización de los contenidos, se parte de la integración del marco teórico en el que se presenta el tratamiento de la doctrina sobre el derecho a la información y su evolución, particularmente el desarrollo de las Tecnologías de la Información y la Comunicación (TIC). En un siguiente eje temático se analiza la naturaleza del derecho humano a la libertad de expresión como un derecho que tiene un valor en sí mismo y como un derecho instrumental de garantía para el estado democrático constitucional. Se incluye en este análisis la trascendencia de la responsabilidad social en el ejercicio de este derecho.

Para finalizar el cuerpo del trabajo se realiza una revisión al régimen jurídico del derecho a la libertad de expresión a través de su evolución constitucional y el posterior desarrollo de la legislación secundaria.

\section{PLANTEAMIENTO}

Frente a la pandemia por COVID-19 que la humanidad enfrenta y el desafío conlleva es necesario partir de una pregunta en materia de libertad de expresión ¿Hasta dónde alcanza nuestra responsabilidad social en el ejercicio del derecho de libertad de expresión? Responder esta pregunta exige repensar con detenimiento la importancia 
del derecho a la libertad de expresión en tiempos de crisis, como una exigencia de la responsabilidad social de cada ciudadano en particular y de los medios, a la altura de la magnitud de esta situación, para dar respuesta a una de las problemáticas en el ejercicio de este derecho.

Entre muchos de los temas que afectan al mundo por la pandemia, uno de ellos es la necesidad de información para la toma de decisiones adecuadas ante la enfermedad, por ello la importancia de la responsabilidad social que se tiene en el ejercicio de la libertad de expresión, como función medular para transmitir información objetiva, fidedigna, con orientación confiable para disminuir el camino de la infección; además para fomentar mensajes de aliento, ayuda, esperanza y solidaridad social.

La humanidad se encuentra frente a riesgos sin precedentes, contra una emergencia de salud pública que se define como un "evento fuera de lo común o imprevisto que exige una intervención o respuesta inmediata y tiene repercusiones graves para la salud pública”. (Organización Mundial de la Salud, 2008, p. 33). La responsabilidad del Estado frente a la pandemia COVID-19 se formalizó a través de los acuerdos o decisiones gubernamentales de cada nación, mediante la declaración de los "estado de emergencia", "estado de excepción", "emergencia sanitaria" o "estados de catástrofe por calamidad pública”, conforme a su régimen jurídico de cada uno. El objetivo fue contener los embates de la pandemia y disminuir en lo posible el incremento exponencial de personas contagiadas.

Las medidas de excepción tomadas por las naciones en el marco del Estado de derecho resultan de inevitable vulneración para los derechos humanos. En efecto, los derechos humanos se han puesto a prueba en estos tiempos de pandemia, la crisis ha obligado a los gobiernos a aplicar políticas, acciones y medidas tendientes a proteger a las personas y a las comunidades. Estás políticas públicas se constituyen a su vez, querámoslo o no, en medidas restrictivas, punitivas y en algunos casos estigmatizantes y discriminatorias. Ante esta situación de afectación irremediable de los derechos humanos, la responsabilidad del Estado se incrementa. Particularmente, se tiene la obligación de mantener informada a la ciudadanía, mediante comunicación verídica, certera, objetiva en el que se explicite su accionar público a través de un sistema de gobierno abierto con el más alto nivel de transparencia.

En concordancia con las medidas tomadas, se exige la respuesta del Estado con la mayor publicidad y transparencia del accionar gubernamental, una claridad que refleje "las realidades y necesidades de todas las personas, que evitará violaciones no intencionadas de los derechos humanos, generará confianza en el gobierno y entre las comunidades” (Organización de las Naciones Unidas, 2020, p. 42).

No hay que olvidar por otra parte, que el Estado no es el único responsable, las circunstancias de la gravedad por la pandemia exigen al ciudadano asumir un sentido del más alto nivel, con responsabilidad social, para contribuir a la difusión a través de la libertad de expresión, en donde la información es un pilar importante para el combate de la propagación de la enfermedad. La acción ciudadana, mediante el ejercicio respon- 
sable de la libertad de expresión apoyará la contención de la pandemia a través de fortalecer a la sociedad con conocimientos, información e ideas sobre medidas preventivas, procedimientos, metodologías, protocolos de actuación para evitar el incremento de los efectos de la pandemia, y en especial, sus efectos en la salud.

Indudablemente la magnitud de la pandemia 2019 genera miedo, incertidumbre social y en algunos casos pánico, por lo que la información se constituye en un elemento importante para mitigar estas reacciones humanas. En efecto, la información como instrumento de comunicación personal y social puede ir cargada de una intencionalidad positiva de una intencionalidad negativa. Se observa que la información que se difunde en los medios de comunicación masiva representa un arma, que por lo tanto puede ayudar o perjudicar a la convivencia humana, porque en ocasiones no aporta para mitigar las necesidades de información y de distracción que requiere el ser humano en momentos tan difíciles como los que está generando la crisis de esta pandemia.

Los medios de comunicación masiva como la prensa escrita y televisión son una fuente de información importante, además de los medios digitales de información como Facebook, Twitter e Instagram, entre otros, tienen una aplicación y uso de impacto fuerte en la comunicación y transmisión de mensajes. Estos mensajes comparten información con frecuencia sin bases científicas ni verídicas y lo que es peor denostación ya sea política, sociales o hacia grupos de personas como mujeres, de edad avanzada, discapacitados, entre otros. El autor Pérez Luño, afirma, que "la presencia de las redes de información y comunicación en los ámbitos jurídicos y políticos ha determinado que se adquiera consciencia de que nunca como hoy se había sentido tan intensamente la necesidad de concebir los valores y derechos de la persona como garantías universales. De esa exigencia de universalidad se infiere la reivindicación de que los derechos de la persona se tutelen sin discriminación alguna por razones de raza, de lengua, de sexo, de las religiones profesadas o de las convicciones ideológicas” (Pérez Luño, 2014, p. 289).

En la revisión de estudios empíricos del tema, se encontró en una investigación realizada por la Organización de las Naciones Unidas para la Educación la Ciencia y la Cultura, UNESCO, con el título "periodismo, libertad de prensa y Covid-19", se explica, que la desinformación ha llegado a un alcance de escala masiva, con los datos siguientes:

"De 112 millones de posteos públicos realizados en 64 idiomas en distintas redes sociales, todos relacionados con la pandemia del COVID-19, los investigadores de la Fundación Bruno Kessler detectaron que un $40 \%$ de los mensajes provenían de fuentes poco fiables. Otro estudio, elaborado por la Fundación Observatorio de "Infodemia” COVID-19, encontró que casi el $42 \%$ de los más de 178 millones de tweets relacionados con el COVID-19 fueron producidos por "bots". El 40\% de ellos, además, fueron calificados como "no fiables", aproximadamente 19 millones de los casi 50 millones de tweets relacionados con el COVID-19, fueron considerados como "in- 
formación o contenido manipulado". Durante el mes de marzo, fueron identificados en Facebook alrededor de 40 millones de mensajes problemáticos relacionados con COVID-19 (acompañadas de advertencias sobre su contenido), así como 8 millones de correos electrónicos fraudulentos sobre coronavirus están siendo bloqueados por Google en su servicio de correo electrónico Gmail, cada día” (Organización de las Naciones Unidas para la Educación, la Ciencia y la Cultura, 2020).

En el mismo sentido, la UNESCO demostró que "la información falsa se ha extendido tan rápido como el propio virus. Estas mentiras han ayudado a allanar el camino de la infección y han contribuido a sembrar el caos en las sociedades que están respondiendo a la pandemia" (Organización de las Naciones Unidas para la Educación, la Ciencia y la Cultura, 2020). En esta misma línea, la Organización Mundial de la Salud ha identificado a la desinformación como "una verdadera segunda enfermedad que acompaña a la pandemia del COVID-19, una sobre abundancia de información, algunas veces precisa, otras no, que dificulta que las personas encuentren fuentes fidedignas y orientación confiable cuando la necesitan" (World Health Organization, 2020).

Ciertamente en estos tiempos de pandemia los medios electrónicos se convirtieron en una importante herramienta para ejercer el libre entendimiento personal; la investigadora Ingrid Brena Sesma explica, que: "durante las emergencias sanitarias algunas personas quieren expresar y compartir sus temores o formular propuestas, y lo hacen a través de los modernos medios electrónicos; blogs, facebook, twittter o en el mejor de los casos a través de foros, conferencias y publicaciones" (Brena Sesma, 2013, p. 27). Agrega la autora, que "la falta de una reglamentación precisa puede originar desinformaciones con resultados contraproducentes que originan un pánico innecesario o que, por el contrario, minimizan las dimensiones del proble$\mathrm{ma}$, y, como consecuencia, las instrucciones ordenadas por las autoridades sanitarias no sean atendidas" (Brena Sesma, Ingrid, 2013, p. 27).

En la búsqueda de una mejor regulación y concientización social para el buen uso de las tecnologías, la Organización de los Estados Americanos, OEA, en unión con la Comisión Interamericana de Derechos Humanos, CIDH, publicó una relatoría especial para el ejercicio de la libertad de expresión en internet, en el que se presenta un estudio sobre los impactos del uso de las nuevas tecnologías y la información en los medios electrónicos.

En esta investigación se sostiene que la libertad de expresión en internet debe de ser ejercida bajo cuatro principios orientadores: acceso, pluralismo, no discriminación y privacidad. El primero de ellos, el acceso, está referido a que "todas las personas deben contar con igualdad de oportunidades para recibir, buscar e impartir información por cualquier medio de comunicación sin discriminación, por ningún motivo, inclusive los de raza, color, religión, sexo, idioma, opiniones políticas o de cualquier otra índole, origen nacional o social, posición económica, nacimiento o cualquier otra condición social” (Comisión Interamericana de Derechos Humanos, 2013, p.7). 
El segundo principio referido al pluralismo se concretiza en el sentido de "maximizar el número y la diversidad de voces que puedan participar de la deliberación pública, es al mismo tiempo condición y finalidad esencial del proceso democrático" (Corte Interamericana de Derechos Humanos, 2009, párr. 199).

El tercer principio orientador de la libertad de expresión en internet, postulado por la OEA y CIDH, es el de no discriminación, conceptualizado como "revertir o cambiar situaciones discriminatorias existentes que comprometan el goce y ejercicio efectivo del derecho a la libertad de expresión de ciertos grupos, en condiciones de igualdad y no discriminación" (Corte Interamericana de Derechos Humanos, 2009, párr. 230).

El cuarto principio orientador de la privacidad enfatiza, que "nadie puede ser objeto de injerencias arbitrarias o abusivas en su vida privada, en la de su familia, en su domicilio o en su correspondencia, ni de ataques ilegales a su honra o reputación", y que "toda persona tiene derecho a la protección de la ley contra esas injerencias o esos ataques" (Convención Americana de Derechos Humanos, 2020).

En efecto, los cambios en las condiciones de vida de la forma en que nos relacionamos y los avances científicos y tecnológicos representan para el ser humano nuevos desafíos, que "se producen a una velocidad cada vez más vertiginosa y afectan decisivamente a los modos y medios de vida, a las relaciones sociales en sus más variados aspectos" (Murillo de la Cueva, 2004, p. 84).

Debe considerarse que, si bien el gobierno tiene una alta responsabilidad para hacer frente a los embates de la pandemia, para atender los problemas de salud de la población hasta la protección de la vida de cada persona, esto no significa que se convierte en el único sujeto obligado, porque hay que reconocer que ninguna nación y que ningún gobierno estaba lo suficientemente preparado para hacer frente a la magnitud de la problemática generada, y que aun cuando los gobiernos atendieran con el máximo de sus capacidades los requerimientos de salud durante la contingencia sanitaria, esta resulta insuficiente, por ello se exige una mayor solidaridad tanto de los individuos en particular como a través de organizaciones, y en esto los medios de comunicación adquieren una particular importancia.

El mundo ya no es el mismo, nuestra forma de pensar, sentir y vivir es diferente en este momento de crisis y será diferente después de ella para quienes quedemos con vida, y en esto la ciencia y la tecnología tendrán que ir aparejadas de su complemento ético como uno de los mejores elementos, solo así podrán seguir siendo uno de los mejores medios para el desarrollo y convivencia humana. 


\section{MARCO TEÓRICO}

El marco teórico de la libertad de expresión es amplio y con diferentes vertientes de análisis, una de estas vertientes está referida a los estudios sobre las tecnologías de información y comunicación (TIC) y la responsabilidad social. Se identifica en las diferentes corrientes teóricas, que este derecho a la libertad de expresión no se plantea como derecho absoluto, sino que por el contrario existe un pronunciamiento hacia derechos y obligaciones para constituir un equilibrio entre libertad y responsabilidad. Este equilibrio se observa también en los sistemas jurídicos de los Estados, tanto en los cuerpos normativos universales y regionales, como en la normatividad nacional interna.

Se consideró sustancial por la naturaleza del tema integrar al análisis teórico algunos aspectos contextuales. Así se encuentra que la libertad de expresión del pensamiento cruza todo el recorrido histórico de la humanidad, se afirma que, "en la época tribal no existía otro medio de comunicación que la palabra oral, por lo tanto la palabra resultaba un medio mítico que permitía la fantasía; captar la historia autentica en esa época resultó no solo imposible sino también distorsionadora. Tres acontecimientos fundamentales de la humanidad han transformado la comunicación" (Mcluhan, 2011, p. 147). En efecto, varios acontecimientos son fundamentales en el devenir de la comunicación: la invención del alfabeto, la invención de la imprenta y el descubrimiento de la electricidad.

La invención del alfabeto por los fenicios permitió objetivar las letras, las palabras y los conceptos gracias a los signos. En esta forma la humanidad pudo comunicarse a través del tiempo y del espacio, transmitir los pensamientos, dejar mensajes y trascender. A partir del alfabeto la captación de la realidad ya no se transmitió solo por la palabra, y que recibió por el oído, sino por la vista para comprender el mensaje escrito, aunque esto fuera por un limitado número de personas con el inconveniente de que podía destruirse con facilidad.

Un segundo momento que marca la evolución de la comunicación fue la invención de la imprenta por Johannef Gutenberg, científico alemán del siglo XV (1397-1478). Con la imprenta las ideas escritas se producen ilimitadamente para su trasmisión en forma masiva. Se afirma que la invención de la imprenta tuvo una influencia decisiva en los grandes movimientos del siglo XVIII, particularmente la revolución francesa mediante la difusión de las ideas liberales de grandes pensadores como Rousseau, Montesquieu, Voltaire, D. Deroti, entre otros. La imprenta permitió el desarrollo de la ciencia a través de la captura de los conocimientos contenidos en los manuscritos que se encontraban en los claustros religiosos y en las primeras universidades del mundo, situación que impulsó el desarrollo de la ciencia en la edad media. Este desarrollo científico produjo a su vez la mecanización que dio como consecuencia la revolución industrial (Macluhan, 2011, p. 147).

El tercer paso sustancial en el desarrollo de la comunicación se da con el descubrimiento de la electricidad que produjo el desarrollo electrónico y que permitió 
la creación de nuevos medios de comunicación como el telégrafo, el teléfono, la radio, la fotografía, el cine, la televisión y la computadora, entre otros. En el presente, el adelanto tecnológico en materia de comunicación es muy amplio, vence toda dificultad de tiempo y espacio, la humanidad tiene la posibilidad de observar "directamente" desde una parte del mundo lo que sucede en el otro extremo del universo, superando toda distancia.

El desarrollo de los medios de comunicación con la creación de una conectividad compleja dio lugar a transformaciones fuertes que impactan en la vida cotidiana, se afirma, que "se trata de un proceso social multifacético y multifactorial, que como lo han enfatizado algunos autores repercute en todas las actividades" (Castells, 2004, p. 54). El avance tecnológico en la conectividad ha creado nuevas relaciones, la producción de prácticas culturales y aunque con grandes carencias y exclusiones se transitó hacia un nuevo paradigma "una sociedad basada en el conocimiento", así lo afirmó Friedrich Hayek, premio nobel de economía (Crovi Druetta, Delia, 2008, p. 229). Más adelante, Petter Brucker acuñó el término "sociedad del conocimiento" en 1993, noción a la que se le agregó el componente informativo para construir el concepto de "sociedad de la información y el conocimiento, SIC".

De la revisión del desarrollo teórico sobre este sobre este tema, se resume del análisis sobre los paradigmas de la tecnología de la información que explica Manuel Castells, la tecnología actúa sobre la información a través de funciones con canales diversos; tiene capacidad de penetración en diferentes niveles culturales y económicos; tiene fuerza de interconexión a través de relaciones e intercambio informativo de contenidos; tiene flexibilidad, toda vez que se adapta y modifica conforme a las necesidades de las organizaciones e instituciones (Castells, Manuel, 2004).

La Sociedad de la información y el conocimiento se constituyó en el centro de atención de las Ciencias de la Comunicación, en el que se considera que existen aspectos sobre los que todavía hay mucho que trabajar y uno de ellos es la responsabilidad social que se aborda en este trabajo. La comunicación como objeto de estudio se ha redimensionado con su incorporación en los diferentes campos de la vida humana como: la educación, el trabajo, la producción de bienes y servicios; el intercambio y la construcción del conocimiento, entre otros. Y en todos estos ámbitos resalta el sentido de la responsabilidad social.

Un enfoque teórico en esta materia es el que sostiene, que el mayor goce de la libertad de un ser humano es el poder desarrollar un pensamiento libre, crítico y propositivo a través del ejercicio de su derecho a pensar en forma personal, sin la interferencia del poder político. La libertad así entendida supone que ningún poder debe interferir u obligar a una persona para que no realice lo que se propone o no desea, así lo sostienen teóricos como Locke, Montesquieu, Constant, Stuart Mill, Tocqueville y Smith, por citar algunos autores clásicos importantes. Michelangelo Bovero, de acuerdo con Norberto Bobbio, explica esta concepción de la libertad en los siguientes términos "los individuos serán mas o menos libres dependiendo de la amplitud de la esfera de comportamientos no regulados por las normas colectivas” (Bovero, Michelangelo, 2012, p. 18). 
A su vez, Norberto Bobbio, desde una visión de la ciencia política afirma que la libertad de pensamiento es una de las "cuatro grandes libertades de los modernos: la libertad personal; la libertad de pensamiento; la libertad de asociación; y la libertad de reunión" (Bobbio, Norberto, 2009, p. 304). Explica el mismo autor que si bien el Estado crea normas para regular el comportamiento social y que el sujeto recibe normas (órdenes, prohibiciones, constricciones, impedimentos) del colectivo al que pertenece, pero dichas normas no abarcan todas y cada una de las esferas de su comportamiento: por lo tanto, los individuos serán más o menos libres dependiendo de la amplitud de la esfera de comportamientos no regulados por las normas colectivas (Bobbio, Norberto, 2009, p. 304).

La doctrina española se destaca por sus aportaciones a la teoría de los derechos humanos, varios juristas, uno de ellos, Gregorio Peces Barba, quien afirma que la libertad de expresión, "es una lucha práctica por la libertad de pensamiento y de investigación”, una lucha del ser humano, "por conquistar su derecho a una investigación racional de una parcela del mundo sensible, que no tiene como objetivo únicamente el desarrollar la actividad científica misma, sino reivindicar una libertad humana que más tarde la amparará" (Peces-Barba, 2003, p. 162). Por su parte, Luis Prieto Sanchis identifica este derecho como libertad de conciencia y expone que, "parece una verdad bastante obvia que jurídicamente la libertad de conciencia no puede referirse a una facultad interna o psicológica, esfera en la que por fortuna el Derecho y el poder aún se muestran incompetentes (cogitationis poenam nemo patitur), sino a una facultad práctica y plenamente social que protege al individuo frente a las coacciones o interferencias que pudiera sufrir por comportarse de acuerdo con sus creencias o convicciones" (Prieto Sanchis, 2006, p. 261).

En el ámbito latinoamericano, Jorge Carpizo y Enrique Villanueva sostienen que "la libertad de expresión constituye un círculo más amplio que engloba al de pensamiento, puesto que es la libertad de pensamiento que se va a exteriorizar y que debe hacerlo sin cortapisas mientras no lesione derechos legítimos de terceros. La libertad de expresión, entonces, se garantiza primordialmente como un derecho fundamental de carácter individual la protección del exponente, aunque pueda tener repercusiones sociales como en el caso de la crítica al gobierno" (Carpizo Jorge y Villanueva Ernesto, 2001, p. 74). En el mismo sentido, Eduardo Ferrer Mac-Gregor explica, que "para el ciudadano común tiene tanta importancia el conocimiento de la opinión ajena o de la información de que disponen otros, como el derecho a difundirla. Así, a la luz de ambas dimensiones, la libertad de expresión requiere, por un lado, que nadie sea arbitrariamente menoscabado o impedido de manifestar su propio pensamiento y representa, por tanto, un derecho de cada individuo; pero implica también, por otro lado, un derecho colectivo a recibir cualquier información y a conocer la expresión del pensamiento ajeno" (FerrerMac-Gregor, 2017, p. 88). En efecto, la libertad de expresión exige una delimitación entre la vida privada del individuo y la esfera del ámbito público.

Frente al desarrollo de las tecnologías de la comunicación, tanto las instituciones y empresas dedicadas a este ramo como los particulares tienen una alta responsabilidad en el ejercicio del derecho a la información, se afirma, que "los medios 
de comunicación son considerados como una institución clave pues al constituirse como una fuente de educación para la sociedad, al lado de la familia y escuela, tienen una tarea central en la búsqueda de soluciones” (Vega Montiel, Aidée, 2008, p. 288). En este contexto los organismos internacionales han puesto especial atención y se han dado a la tarea de emitir recomendaciones a los medios de comunicación en el ámbito internacional con la finalidad de que se analicen las consecuencias de una comunicación distorsionada o incorrecta moral o socialmente con contenido que en ocasiones promueve la violencia, la discriminación, o estereotipos erróneos. La Alta Comisionada de las Naciones Unidas para los Derechos Humanos Michelle Bachelet, reconoció la "necesidad de restringir la información errónea o desinformación que puedan resultar perjudiciales con el fin de proteger la salud pública o cualquier incitación al odio hacia grupos minoritarios, aunque... a la vez los gobiernos pueden tener un interés legitimo en controlar la difusión de la información en un contexto delicado y de inestabilidad, este debe ser proporcionado y proteger la libertad de expresión" (Naciones Unidas, Derechos Humanos, Oficina del Alto Comisionado, 2020).

No puede quedar fuera de la revisión teórica, la consideración de que la libertad de expresión es uno de los derechos que mayormente aporta al avance democrático y al fortalecimiento del estado de derecho. Este derecho constituye el libre pensamiento de las ideas, a través de la expresión de una forma única e individual sobre nuestra propia visión del mundo. Antonio Pasquali expresa, que "si deberás queremos que alguna forma genuina de democracia sobreviva, esta generación habrá de democratizar las comunicaciones, en particular las de vector electrónica, hoy objeto de importantes maniobras oligárquicas" (Pasquali, Antonio, 15 marzo 2007). En efecto, la libertad de expresión se trata de un derecho que tiene un valor en si mismo, en función de los bienes que integra y a la vez se trata de un derecho que tiene un valor instrumental por su garantía efectiva, por constituirse en una garantía efectiva como condición de la democracia y del estado de derecho.

En su esencia, la libertad de expresión se constituye en cada ser humano por procesos deliberativos personales psicológicos y sociológicos, de muy diferente y variada naturaleza como la ciencia, la filosofía, el arte, la tecnología, el derecho, la economía, la política, la religión, el deporte, entre otros. Las posibilidades de expresión del ser humano provienen de la capacidad de pensar y sentir para crear ideas, conocimientos, y aportaciones individuales o colectivas para el desarrollo humano y el bien común.

En un estudio reciente, la Organización de las Naciones Unidas para la Educación la Ciencia y la Cultura, afirma que en esta crisis de pandemia se ha dado una "desinfodemia" y que si bien, "la información fortalece, la desinfodemia desempodera al poner en peligro vidas y conducir a la confusión y la discordia” (Organización de las Naciones Unidas para la Educación, la Ciencia y la Cultura, 2020). Se coincide, en que el derecho a la libertad de expresión debe de ser protegido y reconocido por el Estado de derecho, en el que garantice su respeto, promoción y defensa, a través de acciones públicas como la transparencia y medios de comunicación accesibles a la ciudadanía; es decir, al alcance de todo ciudadano para ejercer este 
derecho. No obstante, este derecho debe ejercerse con responsabilidad bajo una convicción por la verdad, por lo real, y con exactitud de los hechos en esta época de pandemia.

\section{NATURALEZA DEL DERECHO HUMANO A LA LIBERTAD DE EXPRESIÓN}

El entendimiento del derecho humano a la libertad de expresión surge con el nacimiento del constitucionalismo. El reconocimiento como facultad humana, se identifica con el movimiento cultural e intelectual de la ilustración durante los siglos XVIII y XIX, como "una libertad de conciencia desvinculada de toda instancia trascendente”. (Alvear Téllez, Julio, 2001, p. 242). La libertad de expresión adquiere forma de derecho subjetivo con las ideas que permearon en dos acontecimientos que se constituyeron en el devenir histórico en movimientos que revolucionaron la convivencia pública de la humanidad y que influyeron fuertemente. Estos acontecimientos son, por una parte, la Independencia de los Estados Unidos en 1776, y por otra, la Revolución Francesa en 1789.

Se reconoce que dentro del pensamiento más influyente que aportó mayormente a la humanidad en esta etapa, se encuentran las voces de Rousseau, Voltaire, Montesquieu, entre otros. En la claridad de los pensamientos de estos teóricos se rescata que la razón es el principal instrumento para que la humanidad salga de la oscuridad conocida como ignorancia, que la lucha por construir un mundo de personas libres se convierta en lo más importante; libre de sus ideas, de sus creencias, sin opresiones ajenas a su actuar, únicamente dueños de sí mismos y de su intelecto.

En el ámbito normativo, los antecedentes y principios del derecho a la libertad de expresión se ubican en los Bill of Rights de Inglaterra de 1689, en su precepto IX. En América, el antecedente normativo del reconocimiento de este derecho se encuentra en la Constitución Federal de los Estados Unidos, en su primera enmienda que data de 1791.

Posteriormente, como consecuencia de uno de los mayores logros de la Revolución Francesa con la Declaración de los Derechos del Hombre y del Ciudadano de 1789 quedó consagrado este derecho en su precepto 11.

Cabe destacar que, en esta brevísima revisión normativa, la Constitución Española de Cádiz de 1812 en su artículo 371 consagró este magno derecho sobre la libertad de expresión, que alcanzó a ser aplicado en la breve época virreinal que estaba por concluir en México.

En el ámbito internacional, con el avance de la universalización de los derechos humanos en la segunda mitad del siglo XX, y después del sufrimiento de dos guerras mundiales, la humanidad buscó crear alianzas de paz mundial. Se afirma que “a mediados del siglo XX se observó el empeño por promover y tutelar universalmente 
los derechos del hombre y crear instrumentos, instituciones y organismos, en esta materia. Esto es explicable por la cercana vivencia de los regímenes totalitarios en esa época, particularmente del nazismo, el fascismo y los sistemas establecidos en el oriente de este continente, que tanto sufrimiento habían infringido sobre millones de ciudadanos del mundo" (Olmeda García, M, 2014, p. 45). En esta circunstancia, nace la Organización de las Naciones Unidas en 1945 que agrupa a 193 Estados y que ha contribuido substancialmente a la universalización de los derechos humanos, al asumir la obligación de su respeto y garantía.

Así, como parte de la construcción y reestructuración interna de las naciones que estaban quebrantadas por la guerra, se hacía necesario crear ordenamientos internacionales que fomentaran una mejor convivencia con apego a los derechos humanos que habían sido fuertemente vulnerados. Las naciones se convencieron y se sensibilizaron sobre la necesidad de la ampliación y profundización de derechos para lograr contener los impactos de nuevos enfrentamientos armados, como en este caso el derecho a la libertad de expresión.

Uno de los derechos humanos ampliamente reconocidos en el proceso de universalización es el de la libertad de expresión, así se constata en la Declaración Americana de Derechos y Deberes del Hombres de 1948 en su artículo 4to; "Toda persona tiene derecho a la libertad de investigación, de opinión y de expresión y difusión del pensamiento por cualquier medio". El instrumento Universal de mayor rango en el mundo, la Declaración Universal de Derechos Humanos emitida en 1948 consagró también el derecho humano a la libertad de expresión, y lo hizo en su precepto 19 en los siguientes términos "Todo individuo tiene derecho a la libertad de opinión y de expresión; este derecho incluye el de no ser molestado a causa de sus opiniones, el de investigar y recibir informaciones y opiniones, y el de difundirlas, sin limitación de fronteras, por cualquier medio de expresión”.

Continuando con el ámbito universal se encuentra el Pacto Internacional de Derechos Civiles y Políticos de 1966, que entró en vigor el 23 de marzo de 1976 y fue ratificado por el Senado de la República el 24 de marzo de 1981, instrumento que preceptúa el derecho humano a la libertad de expresión en su mandamiento 19, en los siguientes términos:

“1. Nadie podrá ser molestado a causa de sus opiniones.

2. Toda persona tiene derecho a la libertad de expresión; este derecho comprende la libertad de buscar, recibir y difundir informaciones e ideas de toda índole, sin consideración de fronteras, ya sea oralmente, por escrito o en forma impresa o artística, o por cualquier otro procedimiento de su elección.

3. El ejercicio del derecho previsto en el párrafo 2 de este artículo entraña deberes y responsabilidades especiales. Por consiguiente, puede estar sujeto a ciertas restricciones, que deberán, sin embargo, estar expresamente fijadas por la ley y ser necesarias para:

a) Asegurar el respeto a los derechos o a la reputación de los demás;

b) La protección de la seguridad nacional, el orden público o la salud 
o la moral públicas".

En el ámbito regional se encuentra la Convención Americana de Derechos Humanos de 1969 que reconoció el derecho humano a la libertad de expresión, consagrándolo en su precepto 13 en los siguientes términos:

"1. Toda persona tiene derecho a la libertad de pensamiento y de expresión. Este derecho comprende la libertad de buscar, recibir y difundir informaciones e ideas de toda índole, sin consideración de fronteras, ya sea oralmente, por escrito o en forma impresa o artística, o por cualquier otro procedimiento de su elección.

2. El ejercicio del derecho previsto en el inciso precedente no puede estar sujeto a previa censura sino a responsabilidades ulteriores, las que deben estar expresamente fijadas por la ley y ser necesarias para asegurar:

a) el respeto a los derechos o a la reputación de los demás, o

b) la protección de la seguridad nacional, el orden público o la salud o la moral públicas.

3. No se puede restringir el derecho de expresión por vías o medios indirectos, tales como el abuso de controles oficiales o particulares de papel para periódicos, de frecuencias radioeléctricas, o de enseres y aparatos usados en la difusión de información o por cualesquiera otros medios encaminados a impedir la comunicación y la circulación de ideas y opiniones.

4. Los espectáculos públicos pueden ser sometidos por la ley a censura previa con el exclusivo objeto de regular el acceso a ellos para la protección moral de la infancia y la adolescencia, sin perjuicio de lo establecido en el inciso 2.

5. Estará prohibida por la ley toda propaganda en favor de la guerra y toda apología del odio nacional, racial o religioso que constituyan incitaciones a la violencia o cualquier otra acción ilegal similar contra cualquier persona o grupo de personas, por ningún motivo, inclusive los de raza, color, religión, idioma u origen nacional”.

Continuando con el ámbito regional, la Comisión Interamericana de Derechos Humanos emitió la Declaración de Principios sobre Libertad de Expresión en el año 2000. Destaca en esta declaración el segundo principio que determina la igualdad de oportunidades en el ejercicio del derecho a la información y expresión:

“Todas las personas deben contar con igualdad de oportunidades para recibir, buscar, e impartir información por cualquier medio de comunicación sin discriminación por ningún motivo, inclusive los de raza, color, religión, sexo, idioma, opiniones políticas o cualquier otra índole, origen nacional o social, posición económica, nacimiento o cualquier otra condición social”. 
De esta forma la Corte Interamericana determinó, que "dentro de una sociedad democrática es necesario que se garanticen las mayores posibilidades de circulación de noticias, ideas, opiniones, así como el más amplio acceso a la información por parte de la sociedad en su conjunto"

La historia demuestra que la libertad de expresión es el resultado de la lucha incesante del ser humano por su liberación racional, por su respeto a la individualidad y a su dignidad intelectual. Se reconoce además, que en los últimos años este derecho humano enfrenta desafíos ante los avances científicos y tecnológicos que han generado importantes cambios sociales y personales, en el uso y aplicación de las tecnologías. La difusión electrónica, los sistemas de comunicación en redes y medios de información masiva exigen del desarrollo del derecho para la protección más amplia del derecho humano a la información.

\section{RÉGIMEN NORMATIVO DEL DERECHO A LA LIBERTAD DE EXPRESIÓN EN MÉXICO.}

En México el derecho a la libertad de expresión se reconoció desde el primer texto constitucional, en la constitución de Apatzingán de 1814 como un derecho humano del gobernado para manifestar libremente sus ideas, así lo preceptuó el artículo 40 de este magno texto constitucional. Se afirma que esta primera normativa estableció algunas limitaciones a la libertad de expresión "ataques al dogma, es decir, a la religión católica, turbaciones a la tranquilidad u ofensas al honor de los ciudadanos" (Burgoa Orihuela, I, 2013, p. 357). Al inicio de nuestra vida independiente la gran Constitución de 1824 reconoció este derecho en su precepto 50 fracción III, bajo los principios de la Constitución Española de Cádiz.

La Constitución centralista de 1836 consagró también el derecho a la libertad de expresión como una garantía para la expresión escrita en su precepto 2 Fracción VII. En seguimiento al constitucionalismo mexicano se encuentra que las bases orgánicas de 1843 también instituyeron la libertad de expresión como un derecho humano en su artículo 9 Fracción II. Más adelante el acta de reforma de 1847 retomó el criterio de la Constitución de 1824, al reproducir el reconocimiento a la libertad de expresión con el mismo texto de aquella Constitución. Continuando con los antecedentes en México, la gran Constitución de 1857 tuvo como uno de sus méritos sistematizar un eje estructural de los Derechos Humanos, en el que quedó integrado nuevamente el derecho a la libertad de expresión en su sexto mandamiento.

La Constitución vigente de 1917 consagra la libertad de expresión con una mayor amplitud y profundidad de los derechos humanos que la Constitución anterior y con un elevado espíritu y respeto a la individualidad y dignidad humana. Esta Constitución reconoce el derecho humano a la libertad de expresión en sus preceptos 6 y 7. Se determina en el primer precepto la libertad de expresión genérica y en el segundo una libertad de expresión específica referida a la libertad de prensa o de imprenta, que algunos autores denominan libertad de la palabra escrita. 
A 103 años de vigencia de la Carta Magna mexicana, el reconocimiento del derecho humano a la libertad ha sido objeto de seis actualizaciones (Cámara de Diputados, 2014, p. 45). Las reformas normativas al artículo sexto sobre el derecho a la libertad de expresión en la Constitución vigente responden a dos factores, el primero de ellos referido a los derechos que ha adquirido el gobernado en materia de información pública lo que se conoce, como "transparencia y acceso a la información pública” así se establece en el precepto constitucional invocado en su apartado A.

El otro factor que implicó la necesidad de reforma a la materia de libertad de expresión es el avance de las tecnologías y sistemas de información, particularmente sobre radiodifusión y telecomunicación, materia que se preceptúa en el apartado B de este sexto precepto constitucional. El mandamiento constitucional subraya la prohibición de la previa censura en la libre manifestación de las ideas y en el derecho a publicar escritos y no tanto a escribir como también lo determina la Constitución, ya que este acto no puede ser normado prohibitivamente. Respecto a la libertad de prensa, debe considerarse que en el marco del desarrollo democrático tiene un papel necesario para expresarse en el uso de la imprenta. Se afirma que la libertad de prensa, el ataque a ella:

"Se envuelve en sutileza tales como el señalamiento de actos impuestos; la no libre utilización de los medios de comunicación; la discriminación en la distribución de los avisos oficiales; la obligación de hacer inserciones de propaganda política gubernamental; los monopolios de los medios de comunicación; los financiamientos discriminatorios; las limitaciones en el ejercicio de la profesión de periodista; las trabas para la libre agremiación de los periodistas; la imposición de una exigencia de obtener títulos, permisos o licencias para ejercer el periodismo, y otras similares" (Cataño, Luis, 2011, p. 150).

En el análisis de la normativa mexicana sobre la libertad de expresión se desprenden algunas limitaciones que son necesarias para la convivencia. Estas limitaciones conforme al texto constitucional están referidas a que no se puede atacar la moral, a los derechos de terceros o a la vida privada, provocar algún delito, o perturbar la paz o el orden público. Algunos autores consideran que debe incluirse también como limitación a la libertad de expresión lo dispuesto en materia educativa por el artículo tercero constitucional, se afirma que conforme a este precepto la educación está sujeta a exigencias teleológicas de cierto contenido ideológico.

Respecto a la legislación secundaria en materia de libertad de expresión y prensa se encuentra que en mayo de 1923 se inauguró la primera estación de radio en nuestro país, la CYL y la televisión mexicana en 1950. Así, el marco normativo de los medios de comunicación electrónica tiene como primer antecedente la Ley de Comunicaciones Electrónicas de 1926; la Ley de Vías Generales de Comunicación y Medios de Transporte de 1931; la Ley General de Vías de Comunicación de 1932; la Ley de Vías Generales de Comunicación de 1940 y la Ley General de Radio y televisión de 1960. 
Ley General de Radio y Televisión entró en vigor el 19 de enero de 1960 (Cámara de Diputados, 2007, 14). El objetivo de esta ley fue la creación de un marco normativo que regulara la radiodifusión nacional tanto cultural como comercial. Del diario de debates de la Cámara de Diputados se registra que la Diputada Esperanza Téllez Oropeza expuso "es necesario que la radio y la televisión contribuyan no solamente como instrumento de publicidad comercial, sino también, como instrumento fundamental para la educación popular, transmitiendo programas que despiertan en los niños y jóvenes, sentimientos e ideales de moralidad, cultura, civismo, trabajo, respeto y amor a nuestra patria" (Cámara de Diputados, 2007, 14). Asimismo, el Diputado Guillermo Salas Armendáris expuso, "he aquí la característica distintiva de la radio y la televisión, que no se encuentra en las demás vías de comunicación que le pueden ser equiparadas en los términos del artículo primero de la Ley de Vías Generales de Comunicación, en ellas el elemento característico es el de servicio público; concepto éste muy diferente al de servicios de interés público" (Cámara de Diputados, $2007,14)$. Esta ley fue reformada y adicionada en siete ocasiones, la última de ellas el 11 de abril de 2006.

En seguimiento a la legislación secundaria se encuentra la expedición de la Ley Federal de Telecomunicaciones y Radiodifusión que fue promulgada por el órgano legislativo mexicano el 14 de julio de 2014. Esta ley conforme a su artículo segundo transitorio abrogó la Ley Federal de Telecomunicaciones y la Ley Federal de Radio y Telecomunicación. Además, se dejaron sin efectos las disposiciones de la Ley de Vías Generales de Telecomunicación en lo que se opongan a sus disposiciones. Esta Ley de Telecomunicaciones y Radiodifusión ha sido objeto de siete reformas, dos en el año 2015, otra en 2016, dos más en 2017 y las siguientes en 2018 y 2019, siendo la más reciente a realizada el 24 de enero de 2020. El objetivo de esta Ley quedó determinado en su primer precepto, bajo el siguiente texto:

"Artículo 1. La presente Ley es de orden público y tiene por objeto regular el uso, aprovechamiento y explotación del espectro radioeléctrico, las redes públicas de telecomunicaciones, el acceso a la infraestructura activa y pasiva, los recursos orbitales, la comunicación vía satélite, la prestación de los servicios públicos de interés general de telecomunicaciones y radiodifusión, y la convergencia entre éstos, los derechos de los usuarios y las audiencias, y el proceso de competencia y libre concurrencia en estos sectores, para que contribuyan a los fines y al ejercicio de los derechos establecidos en los artículos 6o., 7o., 27 y 28 de la Constitución Política de los Estados Unidos Mexicanos”

\section{REFLEXIONES FINALES}

Las reflexiones que se vierten en este trabajo permiten afirmar que el derecho a la libertad de expresión es un elemento fundamental en los cambios y evolución de las distintas etapas históricas de la humanidad. La libertad de pensamiento es la esencia 
para encontrar el conocimiento, en la búsqueda para comprender la realidad y alcanzar la verdad.

Sin restar importancia al derecho humano a la libertad de expresión, su ejercicio está condicionado a los principios básicos de la convivencia social. Así lo mandata el texto constitucional mexicano cuando dispone que este ejercicio no debe atacar la moral, la vida privada o los derechos de terceros; provoque delito o perturbe el orden público. En esta línea de pensamiento el derecho a la libertad de expresión debe ser ejercido con alta responsabilidad individual y colectiva.

Es evidente que, en el proceso de contingencia de emergencia sanitaria, con la gravedad y magnitud por Covid-2019, el Estado está obligado a aplicar las medidas preventivas necesarias para abatirla. Por lo que toda política pública, programas o acciones que se apliquen deberán garantizar: el acceso a la información, la protección de datos personales, la transparencia, un consentimiento informado, así como el acceso a la justicia y debida reparación.

Por su parte, los particulares debemos de estar involucrados, por lo que la utilización de la comunicación electrónica sobre la que reflexionamos en este trabajo resulta esencial. Debemos aportarle a consolidar una conciencia y responsabilidad ciudadana, así como fortalecer una cultura de la legalidad, para no tener que recurrir a medidas punitivas y detener ese delicado y preocupante camino de restricciones por parte de la autoridad.

En tiempos de pandemia los servicios y sitios electrónicos que el Estado proporcione a la ciudadanía son de vital importancia a través de una información segura y transparente. En el uso de estos medios, el ciudadano se convierte en sujeto activo que opina, que cuestiona y expone sus ideas.

En época de pandemia, la participación de la colectividad se vuelve activa a través de los medios de difusión electrónica, como las redes sociales, con la libertad de exponer y defender su visión y aportar en la mitigación de los efectos negativos de esta contingencia de ataque a la salud. En efecto, en esta circunstancia de tan alto peligro de la humanidad, la libertad de expresión debe de ser ejercida con la más alta responsabilidad, con sentido de solidaridad y cooperación comunitaria.

\section{REFERENCIAS}

1. Alvear Téllez, Julio. (2001) La libertad de conciencia y de religión en la Ilustración francesa: El modelo de Voltaire y de la Encyclopédie, Revista de estudios histórico-jurídicos, n.33.

2. Bobbio, Norberto. (2009). Teoría General de la Política, España, Trotta.

3. Bovero, Michelangelo. (2012). Los desafíos actuales de la democracia, México, Instituto Federal Electoral. 


\section{Brena Sesma, Ingrid. (2013). Emergencias Sanitarias, México, IIJ-UNAM}

5. Burgoa Orihuela, I. (2013). Burgoa las garantías individuales, México, Porrúa.

6. Burgoa Orihuela, Ignacio. (2011). Garantías y amparo en Castro Juventino B, México, Porrúa.

7. Cámara de Diputados, Reformas constitucionales por artículo, recuperado de http://www.diputados.gob.mx/LeyesBiblio/ref/cpeum_art.htm, consultado en 20 de mayo de 2020.

8. Carpizo, Jorge, Villanueva Ernesto. (2001) "El derecho a la información, propuestas de algunos elementos para su regulación en México”, en Valadez Diego, Gutiérrez Rivas Rodrigo, (coords), Derechos Humanos, México, IIJ-UNAM.

9. Castells, Manuel (2004). La era de la información, Economía, sociedad y Cultura, Vol. I, 5ta. Edición, México, Siglo XXI Editores.

10. Cataño, Luis. (2011). El régimen legal de la prensa en México y la libertad de pensamiento y de imprenta en Castro Juventino B, México, Porrúa.

11. Crovi Druetta, Delia. (2008). Apropiación frente a acceso universal. Las TIC en los procesos de democratización, en Vega Montiel A, Portillo, M y Repoll, J., Las claves necesarias de una comunicación para la democracia, México, Asociación Mexicana de Investigadores de la Comunicación A.C, Universidad de Juárez Autónoma de Tabasco.

12. Comisión Interamericana de Derechos Humanos. (2013). Libertad de expresión e internet, Estados Unidos, OEA.

13. Convención Americana de Derechos Humanos, recuperado de https://www.oas.org/dil/esp/tratados_b32_convencion_americana_sobre_derechos_humanos. $\mathrm{htm}$ consultado en 09 de mayo de 2020.

14. Corte Interamericana de Derechos Humanos. (2009) Informe Anual 2009. Informe de la Relatoría Especial para la Libertad de Expresión. Capítulo III (Marco Jurídico Interamericano del Derecho a la Libertad de Expresión). OEA/SerL/V/II. Doc. 51.30 de diciembre de 2009.

15. Ferrer Mac-Gregor, Eduardo. (2017) La libertad de expresión y los medios de comunicación audiovisual en el sistema interamericano de derechos humanos: una nueva aproximación del derecho a recibir y difundir información, en Álvarez, Ignacio, et. al., libertad de expresión a 30 años de la opinión consultiva sobre la colegiación obligatoria de periodistas, América, OEA.

16. Macluhan, Marshal, en Castro Juventino, 2011, Garantías y amparo, México, Porrúa.

17. Murillo de la Cueva, Pablo Lucas. (2004). Derechos fundamentales y avances tecnológicos: Los riesgos del progreso, Boletín mexicano de Derecho Comparado, vol. 37, núm. 109. 
18. Naciones Unidas, Derechos Humanos, Oficina del Alto Comisionado, 2020. Recuperado de: https://www.ohchr.org/SP/NewsEvents/Pages/DisplayNews.aspx?NewsID $=25920 \&$ LangID $=\mathrm{S}$ consultado el 3 de junio 2020.

19. Olmeda García, Marina del Pilar. (2014). Universalización de los derechos humanos, México, Bosch-UABC.

20. Organización de las Naciones Unidas, 2020, Los derechos humanos en tiempo de COVID-19, Ginebra, ONU.

21. Organización de las Naciones Unidas para la Educación, la Ciencia y la Cultura, Periodismo libertad de prensa y Covid-19, recuperado de https://en.unesco.org/sites/default/files/unesco_covid_brief_es.pdf, consultado en 20 de mayo de 2020.

22. Organización Mundial de la Salud, 2008, Guía de la Organización Mundial de la Salud para planificar la comunicación en caso de brotes epidémicos, Ginebra, OMS.

23. Pasquali, Antonio. (15 marzo 2007). Conferencia sobre televisión de servicio público, en el seminario del proyecto el impacto de la televisión pública en la cultura mediática, México, IISUE- UNAM).

24. Peces-Barba Martínez, Gregorio. (2003). Tránsito a la Modernidad y derechos fundamentales, en Peces-Barba Martínez y Fernández García (Coods.), Historia de los derechos fundamentales, Madrid, España, Dykinson.

25. Pérez Luño, Enrique Antonio. (2014). Nuevas Tecnologías y Derechos Humanos, Valencia, España, Tirant lo Blanch.

26. Prieto Sanchis, Luis. (2006). Libertad y objeción de conciencia, en Revista Persona y Derecho, núm. 54.

27. Vega Montiel Aidée, et. al. (2008). Las claves necesarias de una comunicación para la democracia, México, Asociación Mexicana de Investigadores de la Comunicación A.C, Universidad de Juárez Autónoma de Tabasco.

28. World Health Organization. (s.f) Infodemic management-infodemiology. Recuperado de https://www.who.int/teams/risk-communication/infodemic-management, consultado en 20 de mayo de 2020. 